\title{
COMPARISON BETWEEN DIFFERENT DOSES OF NALBUPHINE FOR MANAGEMENT OF POST SPINAL SHIVERING - A PROSPECTIVE, RANDOMISED, DOUBLE BLIND STUDY
} \author{
Manoj Kumar Adak ${ }^{8}$

\begin{abstract}
${ }^{1}$ Associate Professor, Department of Anaesthesiology, Midnapore Medical College, Medinipur. ${ }^{3}$ Assistant Professor, Department of Anaesthesiology, College of Medicine and SD Hospital, Kamarhati. ${ }^{4}$ Assistant Professor, Department of Anaesthesiology, Midnapore Medical College, Medinipur.

${ }^{5}$ Associate Professor, Department of Anaesthesiology, Calcutta National Medical College, West Bengal. ${ }^{6}$ Postgraduate Trainee, Department of Anaesthesiology, Midnapore Medical College, Medinipur. 7 Postgraduate Trainee, Department of Anaesthesiology, Midnapore Medical College, Medinipur. sPostgraduate Trainee, Department of Anaesthesiology, Midnapore Medical College, Medinipur.
\end{abstract} \\ ${ }^{2}$ Assistant Professor, Department of Anaesthesiology, Midnapore Medical College, Medinipur.
}

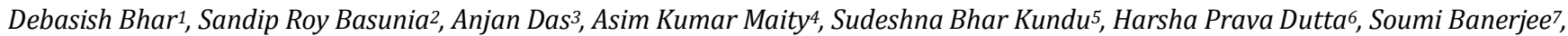

\section{ABSTRACT}

\section{BACKGROUND}

Nalbuphine, a semisynthetic opioid agonist-antagonist, is effective in controlling of post spinal shivering. Till date several studies have compared the efficacy of nalbuphine using different doses but none have suggested the optimum dose for post spinal shivering.

The aim of this study is to compare the efficacy and adverse effects of four doses of nalbuphine $(0.04,0.06,0.08 \mathrm{and} 0.1 \mathrm{mg} / \mathrm{kg})$ and to quantify the optimum dose when used for management of post spinal shivering.

\section{MATERIALS AND METHODS}

In a prospective double-blind randomised control trial, 400 American Society of Anaesthesiologists grade-l (ASA I) patients aged between 18 and 60 years, scheduled for various orthopaedic operations under spinal anaesthesia, who had developed shivering were selected. The patients were divided into four groups (N4, N6, N8 and N10) and treated with $0.04,0.06,0.08$ and $0.1 \mathrm{mg} / \mathrm{kg}$ of nalbuphine respectively when shivering started. Response time (Time required for cessation of shivering), response rate (Measured from the effectiveness of the drug within $15 \mathrm{~min}$. of administration), recurrence of shivering and adverse effects were noted.

\section{RESULTS}

Response rate was significantly higher in N8 and N10 groups compared to other groups $(\mathrm{p}<0.05)$. Response time and recurrence were significantly lower in N8 and N10 groups ( $\mathrm{p}<0.05)$. No significant difference was observed in N8 and N10 groups regarding efficacy. Two patients of N10 group developed transient respiratory depression.

\section{CONCLUSION}

Nalbuphine $0.08 \mathrm{mg} / \mathrm{kg}$ is the optimum dose for controlling of shivering with minimum side effects. Increasing the dose does not improve the efficacy but increases chances of complications.

\section{KEYWORDS}

Nalbuphine, Shivering, Spinal Anaesthesia.

HOW TO CITE THIS ARTICLE: Bhar D, Basunia SR, Das A, et al. Comparison between different doses of nalbuphine for management of post spinal shivering - A prospective, randomised, double blind study. J. Evolution Med. Dent. Sci. 2016;5(101):7438-7443, DOI: $10.14260 /$ jemds/2016/1684

\section{BACKGROUND}

Unintentional perioperative hypothermia, defined as core body temperature below $36^{\circ} \mathrm{C}$, often occurs during anaesthesia and surgery mainly due to direct inhibition of thermoregulation by anaesthetic, decreased metabolism, exposure to low temperature of operating room and body cavity exposure.[1] Shivering is a protective reflex for hypothermia that increases the body heat production through muscle contraction. The incidence of perioperative shivering has been found to be quite high, approximately $40-50 \%$ in

Financial or Other, Competing Interest: None.

Submission 12-11-2016, Peer Review 05-12-2016,

Acceptance 12-12-2016, Published 19-12-2016.

Corresponding Author:

Dr. Debasish Bhar

\#142, Bireswar Chatterjee Street,

Bally, Howrah-711201.

E-mail: debasish_bhar@rediffmail.com

DOI: $10.14260 /$ jemds $/ 2016 / 1684$ different studies.[2] Spinal anaesthesia significantly impairs thermoregulatory system by inhibiting vasoconstriction and thus redistributing core heat to surface below the level of block. These factors predispose patients to hypothermia and shivering.[3]

Both non-pharmacological and pharmacological methods may be used to control shivering during anaesthesia. Nonpharmacological methods using external heating like the use of forced air warming, warming blankets, warmed fluids, etc. to maintain normal temperature of the body are effective but expensive and sometimes are not practical. Pharmacological methods using drugs like meperidine, tramadol, clonidine, doxapram, ketanserin and nalbuphine are effective in controlling shivering but each drug has its own limitations. [4]

Meperidine is widely accepted and highly efficacious for control of shivering but there are situations where healthcare professionals should use meperidine with caution. [5] When meperidine is not available or ideal, treatment of shivering may be done with alternative agents. Among the agents 
recommended for control of shivering, efficacy and safety of nalbuphine is well established.[4] Previous studies had compared nalbuphine with meperidine and tramadol using three different doses of nalbuphine for control of post spinal shivering and observed that all the doses of nalbuphine to be equally efficacious. $[6,7,8]$

But no study till date is available suggesting the optimum dose of nalbuphine to treat shivering. Hence, we planned a prospective, randomised, double blind study comparing the efficacy, haemodynamic changes and adverse effects of four different doses of nalbuphine $(0.04,0.06,0.08$ and $0.1 \mathrm{mg} / \mathrm{kg}$ ) when used for controlling the post spinal shivering.

\section{MATERIALS AND METHODS}

After ethical committee approval and informed patient consent, a prospective, randomised, double blind study was conducted at a tertiary care centre. 400 American Society of Anaesthesiologists (ASA) grade I and II patients of either gender aged 18-65 years scheduled for elective lower limb orthopaedic surgery done under spinal anaesthesia were included in the study.

Shivering was graded using a four point scale (Wrench et al).[9] Grade 0: No shivering. Grade 1: One or more than one of the following: Piloerection, peripheral vasoconstriction, peripheral cyanosis, but without visible muscle activity. Grade 2: Visible muscle activity confined to one muscle group. Grade 3: Visible muscle activity in more than one muscle group. Grade 4: Gross muscle activity involving whole body. Patients who developed either Grades 3 or 4 shivering were included in the study.

Patients with known cardiopulmonary, renal or hepatic disease, hyperthyroidism, urinary tract infection, severe diabetes, autonomic neuropathies, psychiatric disorder, hypersensitivity to nalbuphine and history of substance or alcohol abuse were excluded from the study. Pregnant patient and patients who required blood transfusion during the operative procedure were also excluded from the study.

Patients who met the inclusion criteria and developed shivering (grade 3 or 4 ) after spinal anaesthesia were included in the study and randomly allotted in one of the four groups. Randomisation was done by giving a sealed envelope containing computer generated number to the patient belonging to any of the four groups. Patients belonging to group N4, N6, N8 and N10 received intravenous nalbuphine in the dose of $0.04,0.06,0.08$ and $0.1 \mathrm{mg} / \mathrm{kg}$ respectively. An index anaesthesiologist who was not a part of the study prepared the study drug, at the onset of shivering after opening the envelope. All the study drugs were diluted in $5 \mathrm{~mL}$ of sterile water and prepared in a $5 \mathrm{~mL}$ coded syringe to make the study double blind. The anaesthesiologists conducting the case as well as recording the data were unaware of the dose of the drug administered. The envelope containing randomisation number was enclosed with the data sheet of the patient and was opened at the time of data analysis.

Base line heart rate (HR), oxygen saturation (SpO2), noninvasive blood pressure (NIBP) and electrocardiogram (ECG) was recorded. Venous access was obtained in the upper limb with a 18G catheter and Ringer's lactate (RL) was started at the rate of 20 drops/min. Axillary temperature of patients was measured by digital thermometer with the arm held close to the body.
Under all aseptic and antiseptic precautions, subarachnoid block was administered at the L3-4 or L4-5 interspace with $17.5 \mathrm{mg}$ of $0.5 \%$ hyperbaric bupivacaine with $26 \mathrm{G}$ Quincke needle. After the block was performed, $20 \mathrm{~mL} / \mathrm{kg}$ of RL was transfused over first $30 \mathrm{~min}$. , then @ $10 \mathrm{~mL} / \mathrm{kg} / \mathrm{hr}$.[10] The level of sensory block was recorded with loss of sensation on pinprick.

All operation theatres (OT) were maintained at an ambient temperature of $25^{\circ} \mathrm{C}$ and humidity of $65-70 \%$ using the same mode of air conditioner from at least one hour before the procedure. Patients were covered with drapes but not actively warmed. Intravenous (IV) fluids and drugs were administered at room temperature. All the fluids and drugs were stored in the OT from at least one hour before the procedure and no fluid (both for IV use and for washing the operative field) or drugs from outside the OT were used.

Vital parameters such as HR, NIBP, and SpO2 were recorded at intervals of every $3 \mathrm{~min}$. for first $30 \mathrm{~min}$. and every $10 \mathrm{~min}$. for the rest of the observation period. Continuous ECG monitoring was done throughout the procedure. Supplemental oxygen was administered to all the patients at the rate of $4 \mathrm{~L} / \mathrm{min}$. with face mask.

The attending anaesthesiologist recorded the onset of shivering (time at which shivering started after spinal anaesthesia), severity of the shivering (As per four-point scale), time required for cessation of shivering (response time). Cessation of shivering within $15 \mathrm{~min}$. of administration of study drug was noted as positive response which determined the response rate. Failure to control shivering within $15 \mathrm{~min}$. of administration was regarded as failure and the patient was treated with clonidine $0.5 \mu \mathrm{g} / \mathrm{kg}$ IV.

Incidence of recurrence of shivering and the time interval between recurrence and the study drug administered were also noted. Patients with recurrence of shivering were also treated with clonidine $0.5 \mu \mathrm{g} / \mathrm{kg}$ IV. Adverse effects such as nausea, vomiting, pruritus, bradycardia, hypotension, respiratory depression and sedation score were recorded after the study drug was administered till the end of the procedure and then up to $2 \mathrm{hrs}$. postoperatively.

Duration of spinal anaesthesia and surgery were also recorded. Duration of spinal anaesthesia was recorded by returning of pinprick sensation on the medial aspect of popliteal fossa bilaterally which represents S2 dermatome.[11]

Sedation was graded on a four-point scale as per Filos et al.[12] Grade 1: Awake and alert. Grade 2: Drowsy, responsive to verbal stimuli. Grade 3: Drowsy, arousable to physical stimuli. Grade 4: Unarousable.

Nausea and vomiting were treated with injection ondansetron $4 \mathrm{mg} I V$ as and when required. Hypotension was defined as systolic blood pressure (SBP) $<90 \mathrm{mmHg}$ or $>30 \%$ fall from the baseline value and was treated with $300 \mathrm{~mL}$ of additional fluids, if not responsive within $5 \mathrm{~min}$., with mephentermine $6 \mathrm{mg}$ IV bolus. Blood loss between 500 and $1000 \mathrm{~mL}$ was replaced with hydroxyethyl starch.[13] Blood loss $>1 \mathrm{~L}$ was managed with blood transfusion and the patient was excluded from the study. Bradycardia (60 or less heart beat per min.) was managed with atropine ( $0.6 \mathrm{mg} I V)$.

Patients in whom clonidine was used to treat shivering, adverse effects were not recorded after administration of clonidine. 


\section{Statistical Analysis}

Sample size was calculated considering the response rate as the primary outcome measure. Allowing for the probability of type II error of 0.1 and type I error of 0.05 (Considering the success rate of the $\mathrm{N} 4$ group of $70 \%$, N6 group of $80 \%$, N8 group $90 \%$ and $\mathrm{N} 10$ group $95 \%$ as per the results of previous studies) $(7,8,9)$, it was estimated that 92 subjects per group would be required. To increase the power of the study and to counter exclusion of cases due to blood transfusion, the recruitment target was kept at 100 subjects per group or 400 overall. Categorical data were analysed by Chi- square and Kruskal-Wallis test, while continuous data were analysed by one way ANOVA (when more than two groups were compared) \& Student's unpaired t test (when two groups were compared). $\mathrm{P}$ value of $<0.05$ was considered statistically significant. All data were analysed by SPSS 17 software.

\section{RESULTS}

Demographic profile among the different groups was similar (Table 1). 3 patients of $\mathrm{N} 4$ group, 2 patients of group $\mathrm{N} 6$ and N8 each were excluded from the study as they required intraoperative blood transfusion. 1 patient of N10 group was also excluded due to same reason (Figure 1).

No significant difference in duration of spinal block and surgery was observed between the groups (Table 2). Level of sensory block, baseline body temperature and the amount of intravenous fluid administered was comparable among the groups ( $\mathrm{p}>0.05)$.

There was no significant difference among the groups regarding the onset and severity of shivering. Response time in N4 and N6 group was significantly higher compared to N8 and N10 group $(\mathrm{p}<0.05)$. Response rate is significantly higher and recurrence of shivering is significantly lower in N8 and N10 group compared to other groups $(\mathrm{p}<0.05)$. No significant difference was observed when compared between $\mathrm{N} 4$ and $\mathrm{N} 6$ group or between N8 and N10 group regarding response time, response rate or recurrence (Table 3).

Incidence of hypotension, bradycardia, pruritus, nausea and vomiting were found to be similar among the four groups. Two patients of N10 group had transient fall in SpO2 immediately after giving the study drug which was reversed spontaneously within 1-2 min. and no additional management was required. Sedation score was also comparable in all the groups (Table 4).

\begin{tabular}{|c|c|c|c|c|c|}
\hline & $\begin{array}{c}\text { N4 } \\
(\mathbf{n = 9 7})\end{array}$ & $\begin{array}{c}\text { N6 } \\
(\mathbf{n = 9 8})\end{array}$ & $\begin{array}{c}\text { N8 } \\
(\mathbf{n = 9 8})\end{array}$ & $\begin{array}{c}\text { N10 } \\
(\mathbf{n = 9 9})\end{array}$ & $\begin{array}{c}\mathbf{P} \\
\text { value }\end{array}$ \\
\hline $\begin{array}{c}\text { Weight } \\
(\mathrm{kg})\end{array}$ & $54.33 \pm 5.9$ & $54.46 \pm 5.15$ & $56.63 \pm 5.51$ & $57.26 \pm 7.44$ & $>0.05$ \\
\hline $\begin{array}{c}\text { Height } \\
(\mathrm{cm})\end{array}$ & $160.31 \pm 5.14$ & $159.56 \pm 5.65$ & $159.18 \pm 4.7$ & $162.36 \pm 5.24$ & $>0.05$ \\
\hline $\begin{array}{c}\text { Sex } \\
(\mathrm{M} / \mathrm{F})\end{array}$ & $62 / 35$ & $58 / 40$ & $65 / 33$ & $61 / 38$ & $>0.05$ \\
\hline $\begin{array}{c}\text { Age } \\
(\mathrm{yr} .)\end{array}$ & $41.75 \pm 8.01$ & $39.48 \pm 7.52$ & $39.64 \pm 7.9$ & $40.45 \pm 7.21$ & $>0.05$ \\
\hline \multicolumn{7}{|c|}{ Table 1. Comparison of Demographic Profile } \\
\hline
\end{tabular}

\begin{tabular}{|c|c|c|c|c|c|}
\hline & $\begin{array}{c}\mathrm{N4} \\
(\mathrm{n}=97)\end{array}$ & $\begin{array}{c}\text { N6 } \\
(n=98)\end{array}$ & $\begin{array}{c}\mathrm{N8} \\
(\mathrm{n}=98)\end{array}$ & $\begin{array}{c}\mathrm{N10} \\
(\mathrm{n}=99)\end{array}$ & $P$ value \\
\hline Duration of Surgery (min.) & $57.1 \pm 11.97$ & $62.31 \pm 9.37$ & $59.63 \pm 9.42$ & $59.21 \pm 8.53$ & $>0.05$ \\
\hline Duration of spinal Anaesthesia & $173.64 \pm 34.63$ & $169.46 \pm 31.9$ & $175.21 \pm 32.41$ & $172.91 \pm 32.04$ & $>0.05$ \\
\hline $\begin{array}{c}\text { Intraoperative } \\
\text { Intravenous Fluid (mL) }\end{array}$ & $1797.32 \pm 245.82$ & $1853.59 \pm 238.51$ & $1802.72 \pm 241.72$ & $1781.51 \pm 241.72$ & $>0.05$ \\
\hline $\begin{array}{l}\text { Level of Sensory } \\
\text { Block (Median) }\end{array}$ & T9 & T9 & $\mathrm{T} 8$ & T9 & $>0.05$ \\
\hline $\begin{array}{c}\text { Baseline Body } \\
\text { Temperature }\left({ }^{\circ} \mathrm{C}\right)\end{array}$ & $37.34 \pm 0.13$ & $37.29 \pm 0.12$ & $37.27 \pm 0.13$ & $37.18 \pm 0.11$ & $>0.05$ \\
\hline \multicolumn{6}{|c|}{$\begin{array}{c}\text { Table 2. Comparison of Duration of Surgery, Spinal Anaesthesia, Intraoperative Fluid, Level of Sensory } \\
\text { Block and Baseline Body Temperature }\end{array}$} \\
\hline
\end{tabular}

\begin{tabular}{|c|c|c|c|c|}
\hline & $\begin{array}{c}\mathbf{N 4} \\
(\mathbf{n = 9 7})\end{array}$ & $\begin{array}{c}\mathbf{N 6} \\
(\mathbf{n = 9 8})\end{array}$ & $\begin{array}{c}\mathbf{N 8} \\
(\mathbf{n = 9 8})\end{array}$ & $\mathbf{N 1 0}(\mathbf{n = 9 9 )}$ \\
\hline Onset of Shivering (Min.) & $20.35 \pm 5.91$ & $21.52 \pm 6.11$ & $20.18 \pm 5.8$ & $22.39 \pm 5.82$ \\
\hline Severity of Shivering (Grade) & $3.1 \pm 0.6$ & $2.9 \pm 0.5$ & $3.1 \pm 0.5$ & $3 \pm 0.6$ \\
\hline Response Time & $4.62 \pm 1.28$ & $3.95 \pm 0.95$ & $2.78 \pm 0.46^{*}$ & $2.7 \pm 0.42^{*}$ \\
\hline Response Rate (\%) & $62(63.91 \%)$ & $72(73.46 \%)$ & $97(98.98 \%)^{*}$ & $98(98.99 \%)^{*}$ \\
\hline Recurrence of Shivering (\%) & $24(24.74 \%)$ & $14(14.28 \%)$ & $4(4.08 \%)^{*}$ & $4(4.04 \%)^{*}$ \\
\hline \multicolumn{2}{r}{ Table 3. Post Spinal Anaesthesia Shivering, Response Time and Rate } \\
\hline
\end{tabular}

$* \mathrm{p}<0.05$ when compared with N4 and N6 


\begin{tabular}{|c|c|c|c|c|c|}
\hline & N4 (n=97) & $\begin{array}{c}\text { N6 } \\
(\mathbf{n = 9 8})\end{array}$ & $\begin{array}{c}\text { N8 } \\
(\mathbf{n = 9 8})\end{array}$ & N10 (n=99) & P value \\
\hline Pruritus & 0 & 0 & $1(1.02 \%)$ & 0 & $<0.05$ \\
\hline Nausea Vomiting & $2(2.06 \%)$ & $3(3.06 \%)$ & $4(4.08 \%)$ & $4(4.04 \%)$ & $<0.05$ \\
\hline Respiratory Depression & 0 & 0 & 0 & $2(2.02 \%)$ & $<0.05$ \\
\hline Hypotension & $43(44.33 \%)$ & $41(41.83 \%)$ & $44(44.89 \%)$ & $47(47.47 \%)$ & $<0.05$ \\
\hline Bradycardia & $5(5.15 \%)$ & $4(4.08 \%)$ & $6(6.12 \%)$ & $6(6.06 \%)$ & $<0.05$ \\
\hline Sedation Score & $0.9 \pm 0.043$ & $0.88 \pm 0.032$ & $0.89 \pm 0.051$ & $0.91 \pm 0.048$ & $<0.05$ \\
\hline \multicolumn{7}{|c|}{ Table 4. Perioperative Complications } \\
\hline
\end{tabular}

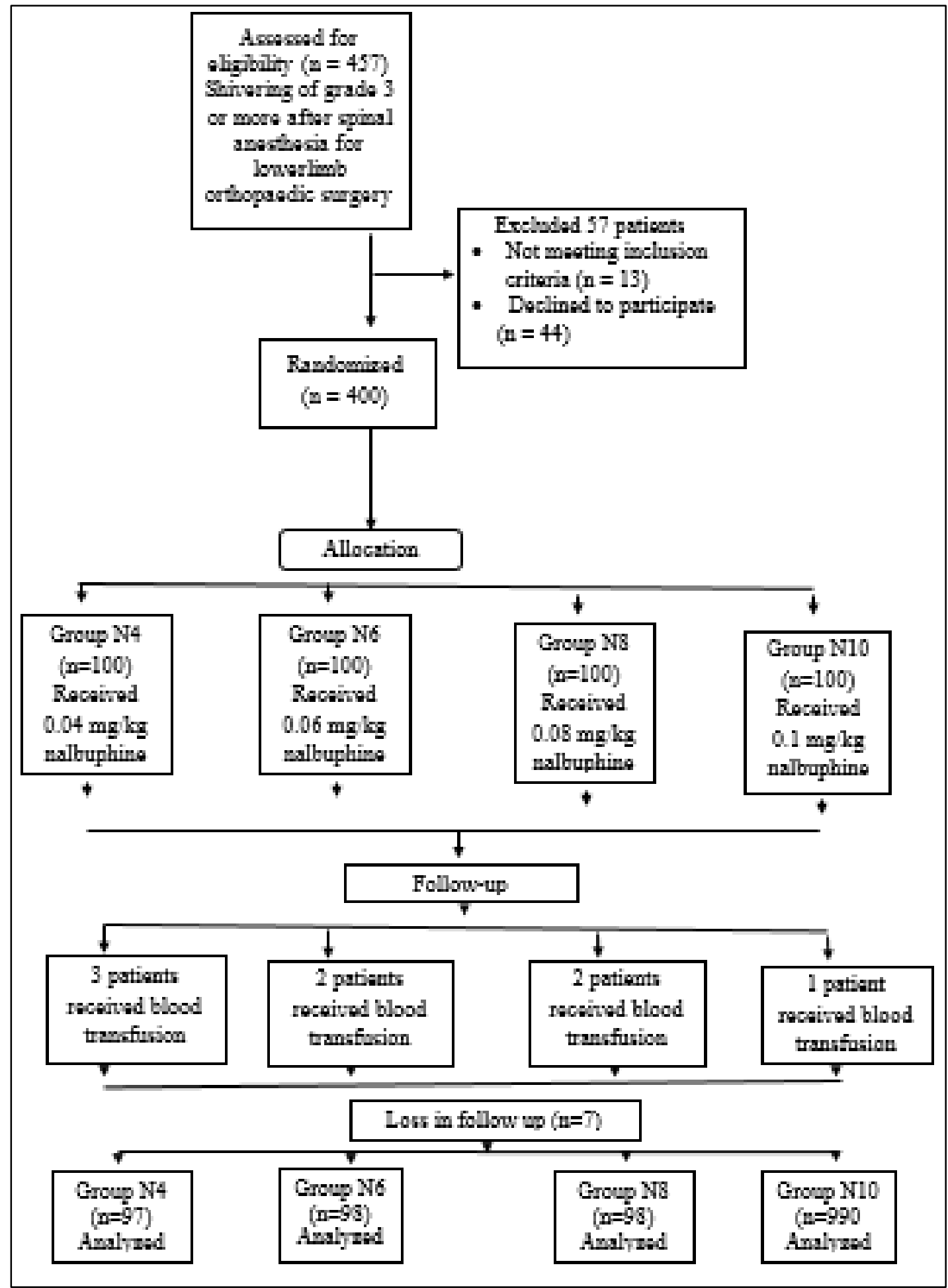

Figure 1. Study Flow Chart 


\section{DISCUSSION}

Shivering is an oscillatory and involuntary muscle contraction which increases metabolic heat production. There are several adverse effects of shivering like arterial hypoxemia, lactic acidosis, raised intraocular pressure and increased oxygen consumption. [14] It also causes interference in monitoring.[15] According to a survey among anaesthesiologists regarding 33 clinical problems by Kranke et el, shivering was ranked eighth in frequency.[16]

Nalbuphine, a semisynthetic agonist-antagonist opioid, is best known for its analgesic properties. It acts as an agonist at kappa receptors and has a high affinity for these receptors. Therefore, nalbuphine's anti-shivering properties are possibly attributed to kappa agonist, yet it is not completely known.[8] Nalbuphine also reduces the shivering and vasoconstriction thresholds, another possible reason for its anti-shivering effects. While the mechanism of action for nalbuphine is still up for debate, studies have found this drug effective for the treatment of shivering. ${ }^{[6-8]}$

Meperidine and tramadol are commonly used opioids for control of shivering by anaesthesiologists in modern days compared to nalbuphine. This is probably due to lack of evidence on the most effective dose for anti-shivering effect of nalbuphine. Scarcity of studies done with nalbuphine for control of shivering may be another contributing factor. Meperidine may cause respiratory depression even in low doses in elderly patient leading to disastrous consequences whereas nalbuphine has limited potential to cause ventilator depression due to its antagonistic activity on mu receptors.[17] On the other hand, incidence of nausea and vomiting with tramadol and nalbuphine are comparable in equipotent dose.[18] Alpha 2 antagonists like clonidine and dexmedetomidine cause haemodynamic changes which may add to the hypotension and bradycardia caused by spinal anaesthesia.[19]

To the horizon of our knowledge, only a few randomised controlled trials done so far comparing efficacy of nalbuphine each using three different doses. Kyokong et al found nalbuphine in the dose $0.05 \mathrm{mg} / \mathrm{kg}$ to be as equally effective as tramadol $0.05 \mathrm{mg} / \mathrm{kg}$ in controlling shivering. [6] Another study by Wang et al concluded that both nalbuphine $(0.08 \mathrm{mg} / \mathrm{kg})$ and meperidine $(0.4 \mathrm{mg} / \mathrm{kg})$ provide a similar rapid and potent anti-shivering effect.[8] Choudhury et al in their study observed that $5 \mathrm{mg}$ nalbuphine is qualitatively superior to 25 $\mathrm{mg}$ of meperidine for control of shivering ${ }^{[7]}$ and also they had taken dose of nalbuphine of $0.086 \mathrm{mg} / \mathrm{kg}$. So from the previous studies, it is observed that nalbuphine is effective in the dose range of 0.05 to $0.086 \mathrm{mg} / \mathrm{kg}$.

In the present study, four different doses of nalbuphine from 0.04 to $0.1 \mathrm{mg} / \mathrm{kg}$ were taken, so that maximum dose ranges are covered which were used in the previous studies.

In our study, we have observed that response rate, recurrence rate and response time all are significantly more in N8 and N10 group compared to other groups. But when we compared between these two groups (N8 \& N10) there is no significant difference. Our study results corroborate with study of Choudhury et al which had almost $100 \%$ response rate when they had used nalbuphine in the dose more than $0.08 \mathrm{mg} / \mathrm{kg}$. [7]

We have also observed that response rate of $73 \%$ and $98 \%$ when $0.06 \mathrm{mg} / \mathrm{kg}$ and $0.08 \mathrm{mg} / \mathrm{kg}$ of the study drug were used. The difference in the response rate from the previous studies where it was around $80 \%(6,8)$ may be attributed to the difference in the study population (pregnant patient in the former study and inclusion of all types of surgery in the other study). Increase in the number of the study population may be another contributing factor.

Recurrence rate was $14 \%$ when we have used $0.06 \mathrm{mg} / \mathrm{kg}$ nalbuphine which is comparable to the study by Kyokong et al where they had used $0.05 \mathrm{mg} / \mathrm{kg}$ nalbuphine.[6] Other studies have not mentioned about recurrence after using nalbuphine for management of shivering. [7,8]

In the present study, clonidine had been used to control shivering in case of recurrence and failure cases as it is a nonopioid and efficacy is well established. It is also found to be more effective than tramadol in controlling shivering. ${ }^{[20]}$ As clonidine may modify the side effects of nalbuphine, complications occurred after administration of clonidine both intraoperatively and postoperatively have not been included in the study.

None of the studies done previously with nalbuphine mention about the response time for control of shivering with nalbuphine. $[6,7,8]$ We have taken response time in account to get an idea about rapidity of the onset of action of nalbuphine.

Complications in all the groups are similar in our study. Only $2 \%$ of the patients developed transient respiratory depression when treated with $0.1 \mathrm{mg} / \mathrm{kg}$ nalbuphine. Nalbuphine has potential for respiratory depression but has a ceiling effect when large dose is used.[21]

Selecting only orthopaedic cases and lack of temperature monitoring throughout the procedure add to limitations of the present study. Absence of placebo group is another limiting factor of this study.

\section{CONCLUSION}

We can conclude that nalbuphine $0.08 \mathrm{mg} / \mathrm{kg}$ is the optimum dose for control of shivering with minimum side effects. Increasing the dose only increases chances of complications.

\section{REFERENCES}

1. Biazzotto $\mathrm{CB}$, Brudniewski $\mathrm{M}$, Schmidt AP, et al. Perioperative hypothermia. Rev Bras Anestesiol 2006;56(1):89-106.

2. De Witte J, Sessler DI. Perioperative shivering: physiology and pharmacology. Anesthesiology 2002;96(2):467-84.

3. Sessler DI. Temperature regulation and monitoring. In: Millar RD. edr. Textbook of anaesthesia. $7^{\text {th }}$ edn. New York: Churchill Livingstone Inc., 2010:1533-56.

4. Charuluxananan S, Trakulthong C, Areejunthawa J, et al. Pharmacological treatment of post-anesthetic shivering: A systematic review and meta-analysis. Asian Biomedicine 2009;3(4):351-63.

5. Latta KS, Ginsberg B, Barkin RL. Meperidine: a critical review. Am J Ther 2002;9(1):53-68.

6. Kyokong O, Tamdee D, Charuluxananan S. Comparison of the efficacy of nalbuphine, tramadol, ondansetron and placebo in the treatment of postanesthetic shivering after spinal anesthesia for cesarean delivery. Asian Biomedicine 2007;1(2):189-94.

7. Choudhury MS, Ahmed S, Haque MM, et al. Shivering control in subarachnoid block by nalbuphine-a comparative study with pethidine. Journal of BSA 2007;20(2):66-9. 
8. Wang JJ, Ho ST, Lee SC, et al. A comparison among nalbuphine, meperidine and placebo for treating postanesthetic shivering. Anesth Analg 1999;88(3):6869.

9. Wrench IJ, Singh P, Dennis AR, et al. The minimum effective doses of pethidine and doxapram in the treatment of post-anaesthetic shivering. Anaesthesia 1997;52(1):32-6.

10. Loubert C. Fluid and vasopressor management for cesarean delivery under spinal anesthesia: Continuing professional development. Can J Anaesth 2012;59(6):604-19.

11. Bhar D, RoyBasunia S, Das A, et al. Repeat spinal anesthesia in cesarean section: a comparison between 10 $\mathrm{mg}$ and $12 \mathrm{mg}$ doses of intrathecal hyperbaric $(0.05 \%)$ bupivacaine repeated after failed spinal anesthesia: a prospective, parallel group study. Anesthesia Essays and Researches 2016;10(2):362-9.

12. Filos KS, Goudas LC, Patroni O, et al. Hemodynamic and analgesic profile after intrathecal clonidine in humans. A dose-response study. Anesthesiology 1994;81(3):591601.

13. Bhar D, RoyBasunia S, Das A, et al. A comparison between intrathecal clonidine and neostigmine as an adjuvant to bupivacaine in the subarachnoid block for elective abdominal hysterectomy operations: a prospective, double-blind and randomized controlled study. Saudi Journal of Anaesthesia 2016;10(2):121-6.
14. Katyal S, Tewari A. Shivering: Anesthetic considerations. J Anaesth Clin Pharmacol 2002;18:363-76.

15. Sessler DI. Temperature monitoring. In: Millar RD. Textbook of anaesthesia. $5^{\text {th }}$ edn. New York: Churchill Livingstone Inc., 1994:1367-89.

16. Kranke P, Eberhart LH, Roewer N, et al. Pharmacological treatment of postoperative shivering: a quantitative systematic review of randomized controlled trials. Anesth Analg 2002;94(2):453-60.

17. Fukuda K. Opioids. In: Miller RD, Eriksson LI, Fleisher LA, eds. Miller's Anesthesia. $7^{\text {th }}$ edn. Philadelphia, PA: Churchill Livingstone 2010:1533-52.

18. van den Berg AA, Halliday E, Lule EK, et al. The effect of tramadol on postoperative nausea, vomiting and headache after ENT surgery. A placebo controlled comparison with equipotent doses of nalbuphine and pethidine. Acta Anaesthesiologica Scandinavica 1999;43(1):28-33.

19. Khan JP, Ferguson CN, Jones RM. Alpha 2 and imidazoline receptor agonist. Their pharmacology and therapeutic role. Anaesthesia 1999;54(2):146-65.

20. Shukla U, Malhotra K, Prabhakar T. A comparative study of the effect of clonidine and tramadol on post-spinal anaesthesia shivering. Indian Journal of Anaesthesia 2011;55(3):242-46.

21. Romagnoli A, Keats AS. Ceiling effects for respiratory depression by nalbuphine. Clin Pharmacol Ther 1980;27(4):478-85. 